\title{
The Suspensory Apparatus and Digital Flexor Muscles of the Llama (Lama glama) 2. The Pelvic Limb
}

\author{
El Aparato Suspensorio y los Músculos Flexores Digitales de la Llama (Lama glama) \\ 2. El Miembro Pélvico
}

"Gheorghe Mircea Constantinescu; "*Shannon Kelly Reed \& "Ileana Anghelina Constantinescu

CONSTANTINESCU, G. M.; REED, S. K. \& CONSTANTINESCU, I. A. The suspensory apparatus and digital flexor muscles of the llama (Lama glama) 2. The pelvic limb. Int. J. Morphol., 26(3):551-556, 2008.

SUMMARY: This paper provides data (text and illustrations) about the digital flexor muscles of the pelvic limb and the / metatarsophalangeal joint, evaluating the suspensory (support) apparatus and weight bearing structures. Similar to the above mentioned paper, a literature search provided incomplete information about these anatomical structures. As in the thoracic limb, unique anatomically variations exist in the pelvic limb of the llama. The caudal tibial muscle is fused with the lateral head of the deep digital flexor muscle (DDF), and the soleus muscle is missing. A symmetrical unexpected lumbricalis pedis muscle was found; the tendons are fusing with the axial branches of the lateral tendon of the long digital extensor muscle. A quadratus plantae muscle, also unexpected is present on the medial aspect of the tarsal region. The superficial digital flexor muscle (SDF) resembles that of the domestic ruminants. The metacarpo/ metatarsophalangeal joints, referred to as the fetlock joints (FJ) are very different from those of the domestic ruminants. Particular structures were found and they will be described and illustrated in the text. The anatomy of the suspensory (support) apparatus in the pelvic limb is evaluated in this paper.

KEY WORDS: Digital flexor muscles; Fetlock joints; Suspensory/stay apparatus; Pelvic limb; Lama glama.

\section{INTRODUCTION}

Similar to the digital flexor muscles in the thoracic limb, an extensive literature search failed to reveal accurate and complete description of the anatomy of the pelvic limb in the llama. Lesbre (1903) described the digital flexor muscles briefly and incompletely. Hubert (1947) and Galotta et al. (1985a) described the muscles of the pelvic limb. The latter only briefly described the caudal muscles of the crus. Galotta et al. (1985b) and Graziotti et al. (2000) mentioned the quadratus plantae muscle.

\section{MATERIAL AND METHOD}

Eight fresh pelvic limbs of adult llamas were dissected. Four pelvic limbs were shipped frozen from Corvallis, OR to Columbia, MO. The animals belonged to individual breeders and were donated to the College of Veterinary Medicine in Corvallis for research. Four pelvic limbs were used fresh from two adult llamas from the Necropsy room of the College of Veterinary Medicine in Columbia, Missouri. They belonged to individual breeders. One llama was euthanized because of an incurable skin condition. The cause of death of the second llama was a gunshot wound to the stomach.

The only method used in this project was the dissection with scalpel, forceps, and scissors. The anatomical terminology is used in accordance to the last edition $\left(5^{\text {th }}\right)$ of the Nomina Anatomica Veterinaria, 2005, an electronic version on the web site.

\section{RESULTS}

The medial head of the gastrocnemius muscle overlaps the popliteus muscle and the SDF in its passage

\footnotetext{
* University of Missouri-Columbia, College of Veterinary Medicine, Columbia, Missouri, USA.

** Oregon State University, College of Veterinary Medicine, 105 Magruder Hall, Corvallis, Oregon, USA.
} 
toward the calcaneus. This tendon joins the tendon of the lateral head of the gastrocnemius forming the calcanean tendon. In contrast to the domestic ruminants, there is no soleus muscle in llamas. The tendon of the medial head of gastrocnemius muscle fuses with the calcanean tendon of the semitendinosus muscle, and is overlapped in an oblique position proximo-distally and medio-laterally by the tendon of the SDF. The calcanean tendon strongly attaches to the calcanean tuber (Fig. 1).

The SDF tendon wraps around the calcanean tendon and attaches firmly to the calcanean tuber as it progresses to the digits (Figs. 1 and 2). In the metatarsal region, it overlaps the DDF tendon and runs distally towards the fetlock, showing similar characteristics to the SDF tendon of the thoracic limb (Constantinescu et al.) (Fig. 3).

The DDF consists of three heads: the lateral head (flexor hallucis longus muscle), the medial head (flexor pedis longus muscle) and a underdeveloped caudal head (caudal tibial muscle). The tendon of the caudal tibial muscle fuses with the tendon of the flexor hallucis longus muscle proximal to the hock (Figs. 1 and 2). Together they glide over the sustentaculum tali, joined distal to it by the tendon of the flexor pedis longus muscle. Before joining the lateral head, the medial head of the DDF glides over the groove of the medial malleolus. At the point of junction of the medial and lateral head, the quadratus plantae muscle attaches. The latter originates from the medioplantar aspect of the calcaneus (Fig. 4). It is a slender muscle protected by the flexor retinaculum. This muscle is not found in the domestic ruminants, only in domestic carnivores, and in the llama it has the appearance of a vestigial muscle.

The tendon of the DDF continues its run deep to the SDF tendon in a similar manner as the same tendon of the thoracic limb (Constantinescu et al.) (Fig. 3). Proximal to the fetlock, at the point where the DDF tendon splits for each digit, the lumbricalis pedis muscles originate (usually two symmetrical muscles in the pelvic limb). They continue with very thin tendons which join the branches of the lateral tendon of the long digital extensor muscle (Fig. 3).

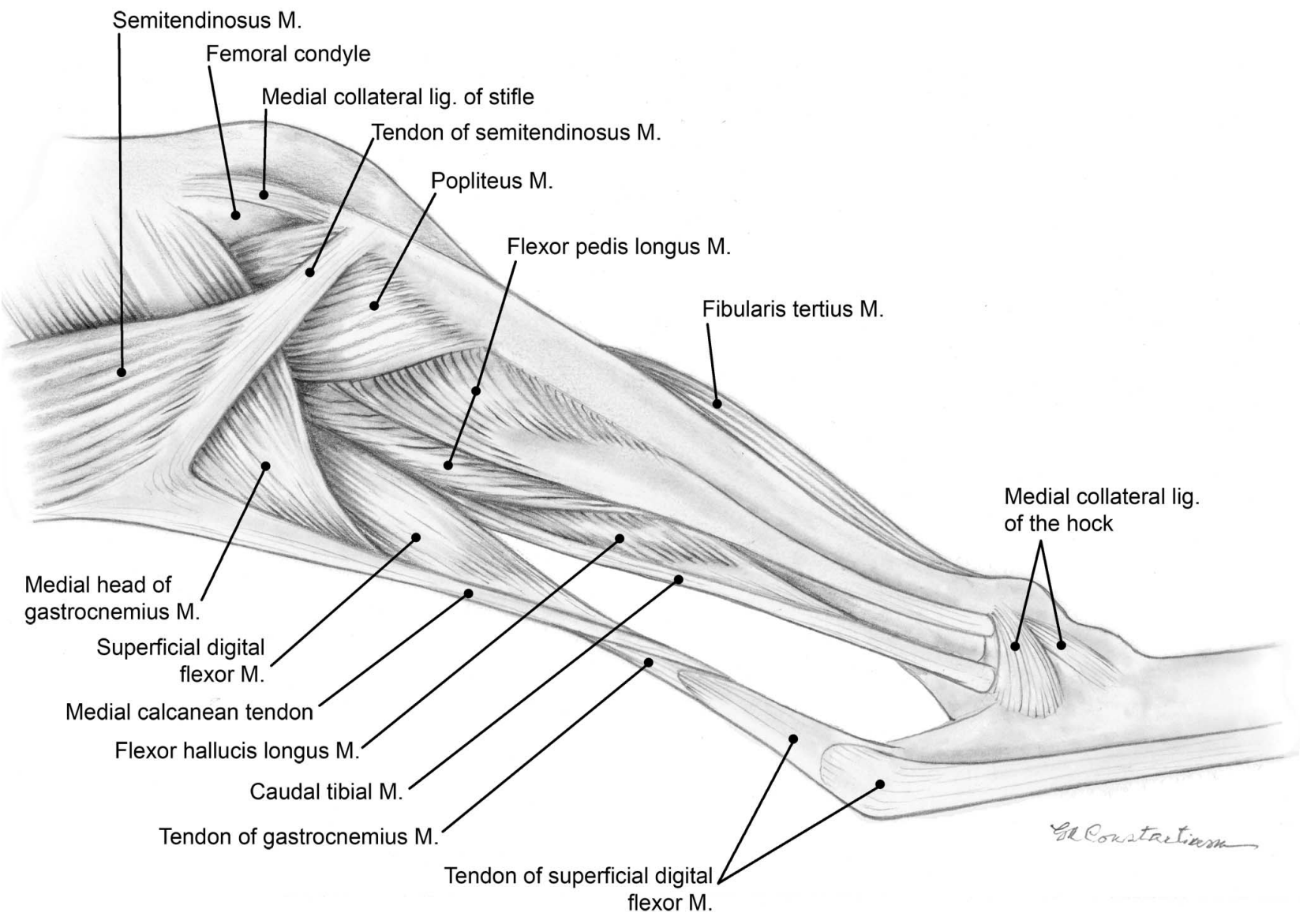

Fig. 1. Medio-caudal aspect of flexor digital muscles - left pelvic limb in the crus. 


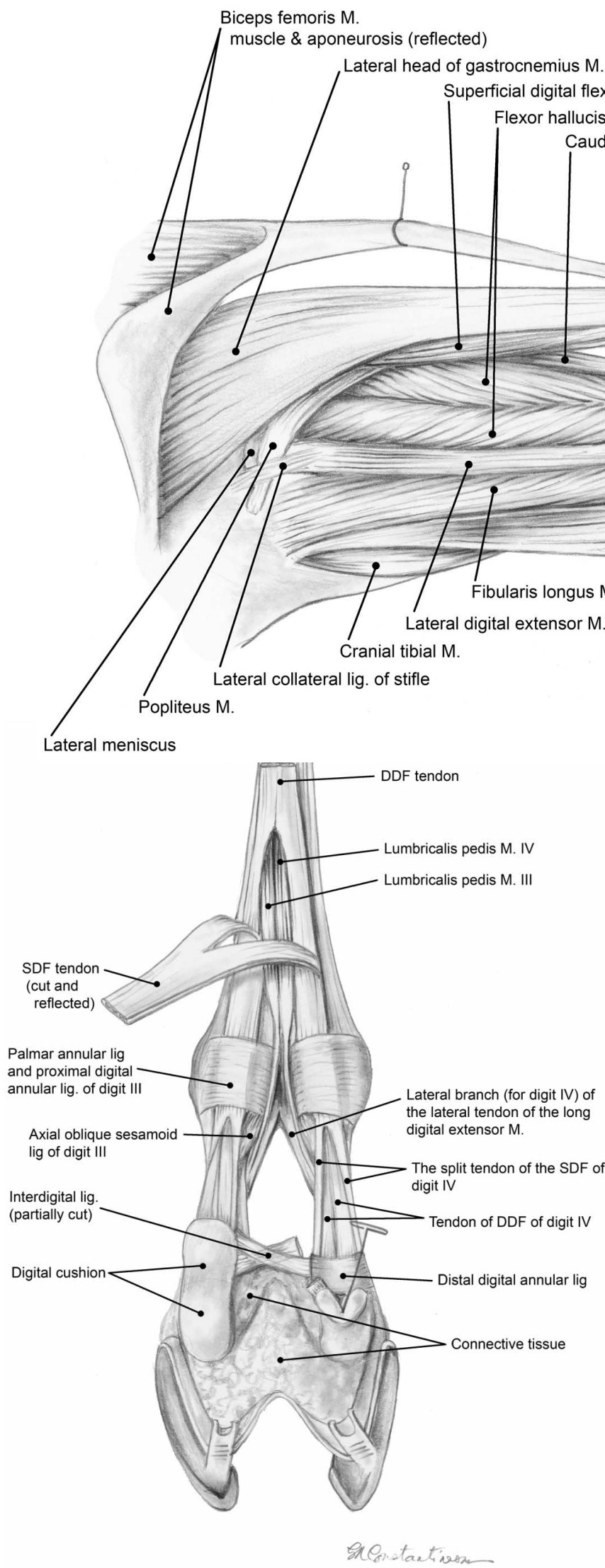

Fig. 3. Plantar aspect of digital region - roght pelvic limb.

It is important to mention that similar to the thoracic limb, there are no distal sesamoid bones in the pelvic limb. Additionally, the distal scutum is strongly attached to the plantar aspect of the third phalanx.

The fetlock joints of the thoracic and pelvic limbs are very similar to each other. The following description uses terms pertaining to the pelvic limb. The fetlock joints (FJ) are different from the domestic ruminants, and have some features resembling to the horse. First, the attachment of the IM on the facies $\mathrm{m}$. interossei of the proximal sesamoid bones (PSB) is cartilaginous. This can be seen on the dorsal aspect of the IM, by reflecting it. At the point of attachment, there is a smooth transition between the tendon and the bones, which elongates the appearance of the PSB. In fact, the dor- 
sal articular surface of the PSB is shorter than the condyles of the head of the metatarsal bones and needs an extension. During the movements of the FJ, the cartilage of the insertion point of the IM protects the tendon against injuries (Fig. 5). After removing the digital flexor tendons the attachment of the IM appears to continue to the proximal scutum in a plantar view (Fig. 6). Additionally, there is an interdigital metatarsointersesamoid ligament (Fig. 5 ), which is found only in the horse under the name of the metatarsointersesamoid lig. (and not "interdigital", due to the single digit in the horse). Also similar to the horse, the oblique sesamoid ligaments are found in llamas (Fig. 6). Interdigital metatarsophalangosesamoid ligaments are found in llamas, versus interdigital phalangosesamoid ligaments in the domestic ruminants. The short sesamoid ligaments and the cruciate sesamoid ligaments are present, as well as the plantar ligaments.
Each metatarsophalangeal joint is provided with a prominent joint capsule only on the dorsal aspect. The joint capsule ends at the axial and abaxial collateral ligaments of the corresponding digit. Each set of PSB is connected by a plantar ligament (Fig. 5). From the base of the PSB the following ligaments originate on each digit (Figs. 5 and 6): the short ligaments attached to the proximal phalanx, the cruciate ligaments which are very short and located between the previous ligaments, and the very strong oblique sesamoid ligaments attached to the plantar aspect of the proximal phalanx. The two sets of PSB (precisely the axial sesamoid bones) are connected by the interdigital intersesamoid ligament and the interdigital metatarsophalangosesamoid ligaments. The former sends a thin ligament looking like a fibrous band to the intertrochlear notch of the metatarsal bones. The latter are not mentioned in the N.A.V. and it is for the first time that these ligaments are described in llamas.

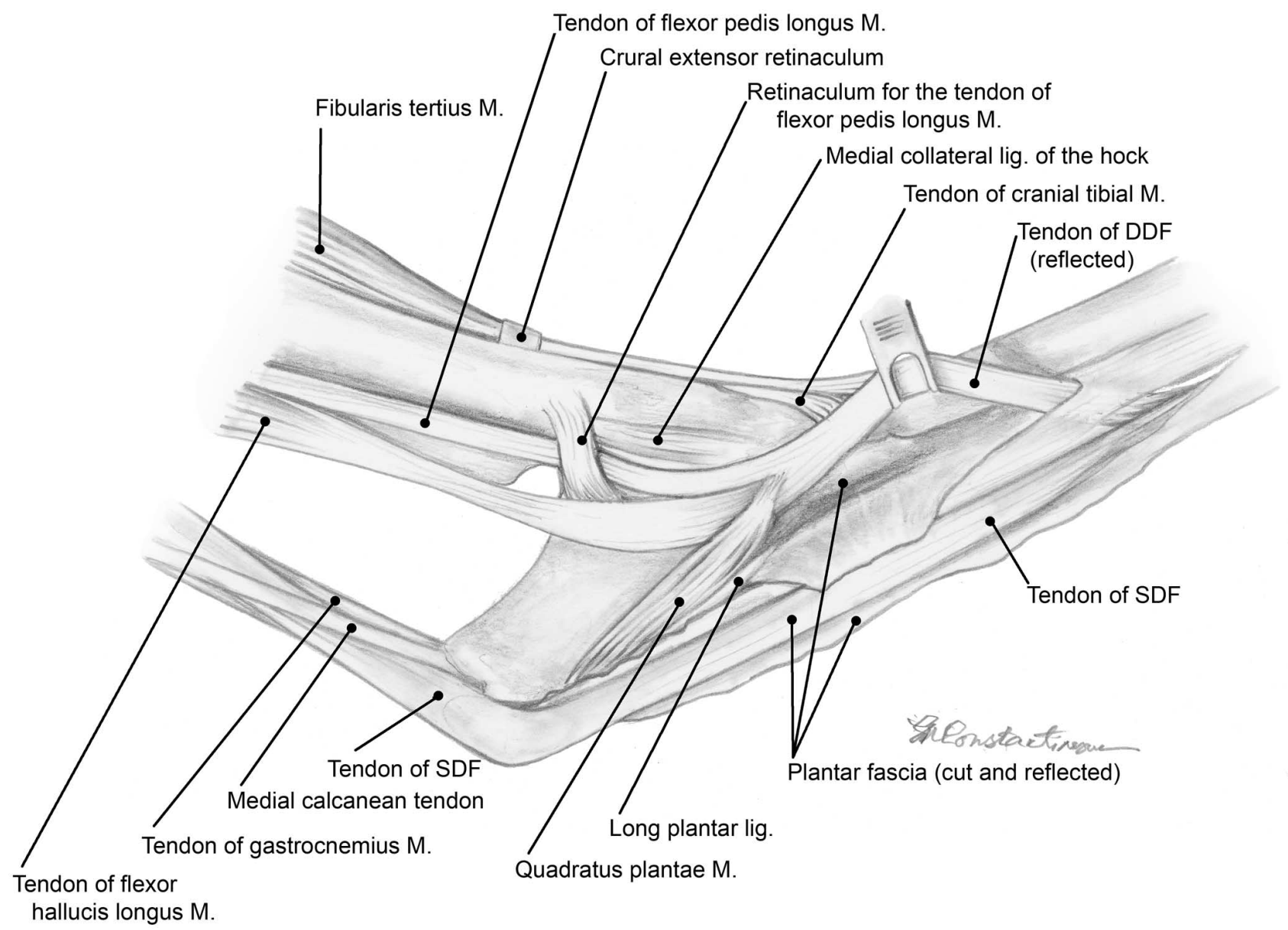

Fig. 4. The quadratus plantae muscle and adjacent structures - left pelvic limb in the hock. 
Fig. 5. The fetlock joints - left pelvic limb. dtso-plantar view of metatarsal bones, dorsal view of proximal sesamoid bones and of interosseous muscles (reflected).

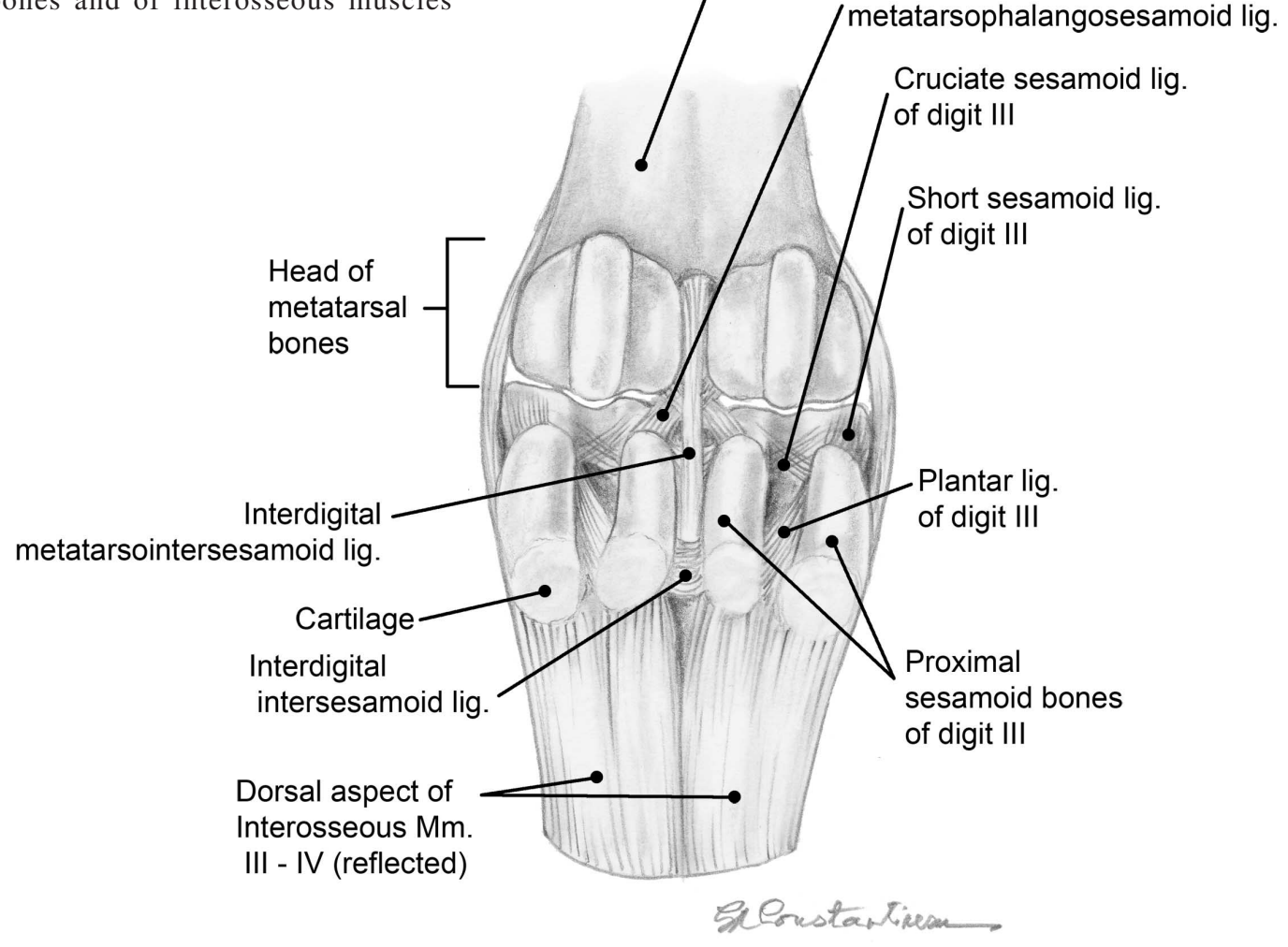

Fig. 6. The fetlock joints - left pelvic limb. Plantar aspect of fetlock joints (the SDF $\&$ DDF tendons are removed).

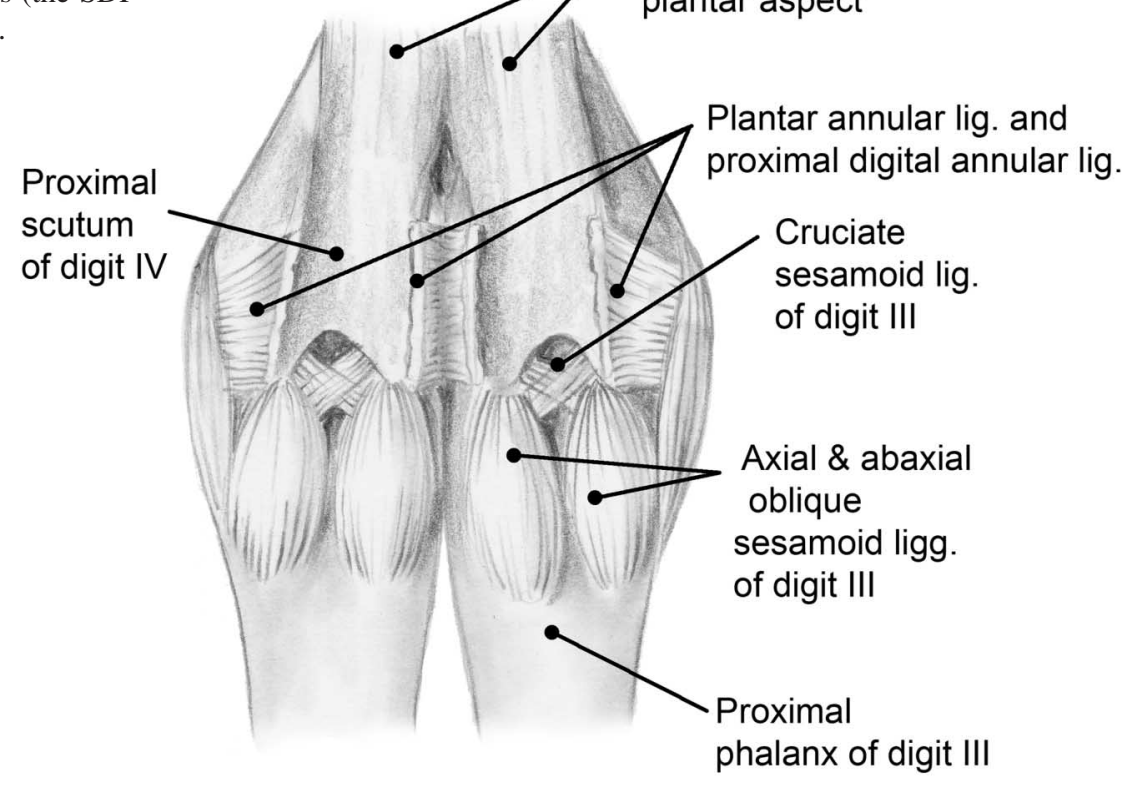




\section{DISCUSSION}

Galotta et al. (1985a) did not mention the caudal tibial muscle, while Lesbre and Hubert acknowledged its presence. Lesbre mentioned a small accessory muscle isolated from the base of the calcaneus, not identifying it as the quadratus plantae muscle. The same author described only one lumbricalis muscle of the pelvic limb. Galotta et al. in 1985 falsely consider the vinculum as the attachment of the DDF tendon on the plantar surface of the middle phalanx (this attachment doesn't exist) similar to our findings in the thoracic limb.

Comparing to the suspensory apparatus in the llama to that of the horse, there is no reciprocal apparatus or accessory ligament of the DDF tendon in llamas. A true stay apparatus is specific to the horse only. However, a suspensory apparatus particular to the llama can be considered for both limbs in the digital area. First, the limbs of the llamas support the body weight on the last two phalanges, system which is not proper to the domestic ruminants. The very strong oblique sesamoid ligaments oppose the traction of the IM. They are not found in the domestic ruminants, but in the llamas they are very well developed for mechanical reasons. In addition, the interdigital metacarpo/metatarsointersesamoid ligament is not found in the domestic ruminants, but in llamas it consolidates the relationships between the metacarpal/ metatarsal bones, the proximal phalanges and the corresponding PSB. The flexibility of the FJs and the limitation of the overextended joints are due to the complexity of ligaments, some of them specific to this species.

In conclusion, we can homologate several structures of the pelvic limb as corresponding to a species specific suspensory (support) apparatus bearing the weight of the body: the interosseous muscle strongly attached to the proximal sesamoid bones, the presence of the interdigital metacarpo/metatarsointersesamoid ligament, the interdigital metacarpo/metatarsophalangosesamoid ligament, and the oblique sesamoid ligaments.

CONSTANTINESCU, G. M.; REED, S. K. \& CONSTANTINESCU, I. A. El aparato suspensorio y los músculos flexores digitales de la llama (Lama glama) 2. El miembro pélvico. Int. J. Morphol., 26(3):551-556, 2008.

RESUMEN: El presente artículo ofrece datos (texto e ilustraciones) sobre el músculo flexor digital del miembro pélvico y la articulación metatarsofalángica, evaluando el aparato suspensorio (de apoyo) y el peso que soportan estas estructuras. La literatura proporciona información incompleta acerca de estas estructuras anatómicas. Al igual que en el miembro torácico, existen variaciones anatómicamente únicas en el miembro pélvico de la llama. El músculo tibial caudal se fusiona con la cabeza lateral del músculo flexor digital profundo (FDP), y el músculo sóleo no existía. Fue encontrada una simetría inesperada del músculo lumbrical del pie; los tendones se encontraban fusionados con las ramas axiales del tendón lateral del músculo extensor digital largo. Un músculo cuadrado plantar, se encontraba presente en la cara medial de la región tarsal. El músculo flexor digital superficial (FDS) se asemeja al de rumiantes domésticos. Las articulaciones metacarpo/metatarsofalángicas, denominadas articulaciones del nudillo (AN) son muy diferentes de las de rumiantes domésticos. Fueron encontradas estructuras particulares que se describen e ilustran en el texto. Se evalúa la anatomía del aparato suspensorio (de apoyo) en el miembro pélvico.

PALABRAS CLAVE: Músculos flexores digitales; Articulaciones del nudillo; Aparato suspensorio/de apoyo; Miembro pélvico; Lama glama.

\section{REFERENCES}

Hubert, B. Contributión à l'étude myologique du membre pelvien du Lama glama L. Thèse pour le Doctorat Vétérinaire. Ecole Nationale Vétérinaire d'Alfort. París, Copedith, 1947.

Galotta D. R.; Stöver, E. \& Galotta, J. M. Caudal muscles of the crus of the Llama (L. glama guanicoe f. d. glama L 1758). London, XII International Anatomical Congress, 1985a.

Galotta, D. R. ; Galotta, J. M. \& Stöver, E. El músculo cuadrado plantar de la Llama. Rev. de Cs. Agrarias UCA, 6(3-4):55-7, 1985b.

Graziotti, G.; Rios, C.; Rodriguez Menendez, J. \& Victorica, C. L. Arteries of the hindfoot of the llama (Lama glama). Anat. Histol. Embryol., 29(5), 273-6, 2000.
Lesbre, F. X. Recherches anatoomiques sur les camélidés. Archives du Museum D'Histoire Naturelle de Lyon. Lyon, Henri Georg Éditeur, 1903.

\section{Correspondence to:}

Dr. Gheorghe Mircea Constantinescu

University of Missouri-Columbia

College of Veterinary Medicine, 1600 E. Rollins

65211-5120

Columbia, Missouri - USA

Ph. (573) 882-7249 or 7228, Fax (573) 884-6890

E mail: ConstantinescuG@missouri.edu

Received: 17-01-2008

Accepted: 28-04-2008 